\title{
An Observing System Simulation Experiment (OSSE) to Assess the Impact of Doppler Wind Lidar (DWL) Measurements on the Numerical Simulation of a Tropical Cyclone
}

\author{
Lei Zhang and Zhaoxia Pu \\ Department of Atmospheric Sciences, University of Utah, 135 S 1460 E, Rm. 819, Salt Lake City, UT 84112, USA \\ Correspondence should be addressed to Lei Zhang, lsea.zhang@utah.edu
}

Received 31 December 2009; Revised 1 April 2010; Accepted 10 April 2010

Academic Editor: Song Y. Hong

Copyright () 2010 L. Zhang and Z. Pu. This is an open access article distributed under the Creative Commons Attribution License, which permits unrestricted use, distribution, and reproduction in any medium, provided the original work is properly cited.

\begin{abstract}
The importance of wind observations has been recognized for many years. However, wind observations-especially threedimensional global wind measurements-are very limited. A satellite-based Doppler Wind Lidar (DWL) is proposed to measure three-dimensional wind profiles using remote sensing techniques. Assimilating these observations into a mesoscale model is expected to improve the performance of the numerical weather prediction (NWP) models. In order to examine the potential impact of the DWL three-dimensional wind profile observations on the numerical simulation and prediction of tropical cyclones, a set of observing simulation system experiments (OSSEs) is performed using the advanced research version of the Weather Research and Forecasting (WRF) model and its three-dimensional variational (3DVAR) data assimilation system. Results indicate that assimilating the DWL wind observations into the mesoscale numerical model has significant potential for improving tropical cyclone track and intensity forecasts.
\end{abstract}

\section{Introduction}

Although numerical weather prediction (NWP) models have been improved significantly over the past two decades, the forecast accuracy of high-impact weather events, such as tropical cyclones, is still a challenging problem in practical applications. Since most tropical cyclones occur over tropical oceans, where conventional observations are sparse, large uncertainties are presented in the numerical simulations and predictions due to inaccurate initial conditions. Remote sensing techniques provide an opportunity to observe the atmosphere, especially the atmospheric temperature, moisture, and ozone over the oceans either directly or indirectly. However, among all the variables used to represent the state of the atmosphere, wind measurements are the most limited, although the importance of wind observations for meteorological analysis has been recognized for many years [1-3]. Previous studies indicate that wind information plays an important role in improving the tropical and extratropical cyclone forecasts [4-14]. However, the current global observing system does not provide a uniform distribution of tropospheric wind measurements, especially in the tropics, southern hemisphere, and northern hemispheric oceans, where conventional observations are very sparse. During the past two decades there have been several satellites measuring wind over the oceans, such as the Geosat altimeter, the National Aeronautics and Space Administration (NASA) Scatterometer (NSCAT), Quick Scatterometer (QuikSCAT), the Special Sensor Microwave Imager (SSM/I), and European Space Agency Remote Sensing Satellites (ERS-1/2). QuikSCAT, which was launched in 1999, can provide ocean surface wind observations. Some previous studies $[15,16]$ showed that assimilating QuikSCAT ocean surface wind observations had a positive impact on improving the numerical simulation and prediction of tropical cyclones. Other studies also indicated that including SSM/I wind information had the potential to improve low-level wind simulation [15]. Since SSM/I only provides ocean surface wind speed measurements, not wind directions, this makes the viewing of SSM/I winds confusing. NSCAT wind also showed a positive impact on tropical cyclone simulation [10], but NSCAT only provides near-surface wind vectors 
over the oceans. Therefore, although wind measurements have been improved to some extent during the past years, the direct three-dimensional global wind profile measurement is still limited. None of the aforementioned satellite instruments directly provides wind profile information in the troposphere.

In recent years, it has been proposed to use Doppler wind lidar (DWL) to measure the three-dimensional wind profiles either globally, with a polar-orbiting satellite [17], or regionally, if mounted on aircraft [18]. The DWL uses a technique similar to that of Doppler radars except that a lidar emits pulses of laser light instead of radio waves [18, 19]. It is able to measure the wind profile from surface to high altitudes (e.g., $18 \mathrm{~km}$ ) with very high vertical resolution. The objective of this paper is to examine the potential impact of DWL measurements from the polar-orbiting satellite on the numerical simulation and prediction of tropical cyclones.

Generally, the best way to examine the impact of the proposed observations on NWP is to conduct Observing System Simulation Experiments (OSSEs) [20-22]. There are several advantages of OSSEs: such as easy control of the experiments, precise knowledge of the data properties and errors, and knowledge of the truth, and so forth [21]. In this study, the potential impact of the simulated space-based DWL three-dimensional (3-D) wind profile measurements on the numerical simulation and prediction of tropical cyclone formation and intensification is examined by conducting a set of OSSEs using the advanced research version of the weather research and forecasting (WRF) model and its three-dimensional variational (3DVAR) data assimilation system.

The advanced research version of the mesoscale community WRF model and its 3DVAR system are briefly described in Section 2. Details of OSSEs setup are presented in Section 3. The potential impact of assimilating spacebased three-dimensional wind profiles on tropical cyclone simulation and prediction based on OSSE results is examined in Section 4. Conclusions and discussions about some practical issues are addressed in Section 5.

\section{Numerical Model and Data Assimilation System}

2.1. The WRF Model. The advanced research version WRF model (ARW) was developed by the Mesoscale and Microscale Meteorology (MMM) Division of the National Center for Atmospheric Research (NCAR). The ARW is designed to be a flexible, state-of-art atmospheric simulation system. This system is suitable for use in a wide range of applications across scales ranging from meters to thousands of kilometers. It is useful for studies of physical parameterizations, data assimilation, real-time NWP, and so forth. The ARW model is a fully compressible and non-hydrostatic model with a terrain-following vertical coordinate. The horizontal grid system is the Arakawa Cgrid. The ARW solver uses the Runge-Kutta 2nd and 3rd order time integration schemes and 2nd and 6th order advection schemes in both horizontal and vertical directions.
A small step time-split scheme is used for acoustic and gravity wave modes. A complete description of the WRF model can be found in the WRF users guide posted on the website: http://www.mmm.ucar.edu/wrf/users/docs/. For this study, the version 3.0.1 was used in all experiments.

2.2. The WRF 3DVAR System. The WRF 3DVAR assimilation system is designed to provide optimal initial and boundary conditions to the WRF model by using various observational information sources both from conventional and nonconventional measurements, such as satellite radiance data, radar observations, GPS measurements, and so forth. The WRF 3DVAR is a multivariable data assimilation system. The control variables are the stream function, the unbalanced part of potential velocity, the unbalanced part of temperature, the unbalanced surface pressure, and pseudo relative humidity. The background error correlation is generated using a so-called NMC method [23], which is a popular method for estimating climatological background error covariances. In the NMC method, the background errors are approximated by averaging the statistics of the differences between two sets of the model forecasts (such as $24 \mathrm{hr}$ and $12 \mathrm{hr}$ forecasts) valid at the same time. The observation errors are assumed to be uncorrelated, so the observation error covariance matrix is a diagonal matrix. A detailed description of the 3DVAR system can be found in Barker et al. [24, 25].

\section{Experimental Designs}

3.1. Case Description. In reality, we do not know the true state of the atmosphere. In order to quantitatively assess the potential impact of the proposed observing systems on the NWP models in OSSEs, we need to simulate an atmosphere status that has the same statistical behavior as that of the real atmosphere. The simulated "true" atmosphere status is the so-called nature run (NR). The accuracy of NR is important to an OSSE because the OSSE results cannot show the realistic observational impact on numerical weather simulation and predictions unless the simulated "true" atmosphere represents most of the characteristics of the real atmosphere.

In order to support community needs in OSSEs, the European Center for Medium-Range Weather Forecasts (ECMWF) produced global nature runs using a spectral prediction model in July 2006 [26]. There are two nature runs with different resolutions: one is at T511 (about $40 \mathrm{~km}$ horizontal resolution) spectral truncation with 91 vertical levels and 3-hour frequency output from 1200 UTC May 1 2005 to 0000 UTC June 12006 . The other one is the higher resolution simulation at T799 (about $25 \mathrm{~km}$ horizontal resolution) spectral truncation with 91 vertical levels and hourly output from September 272005 to November 12005. For simplification, we refer these two global nature runs as T511 NR and T799 NR, respectively. According to the early evaluation by Reale et al. [27], the large-scale structure of the T511 NR is very realistic. In some cases, smaller scale structures in the T511 NR are more realistic than in the 


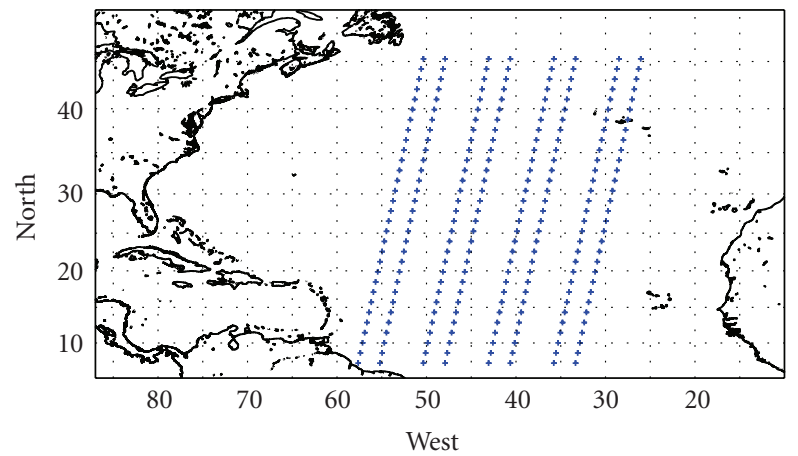

(a)

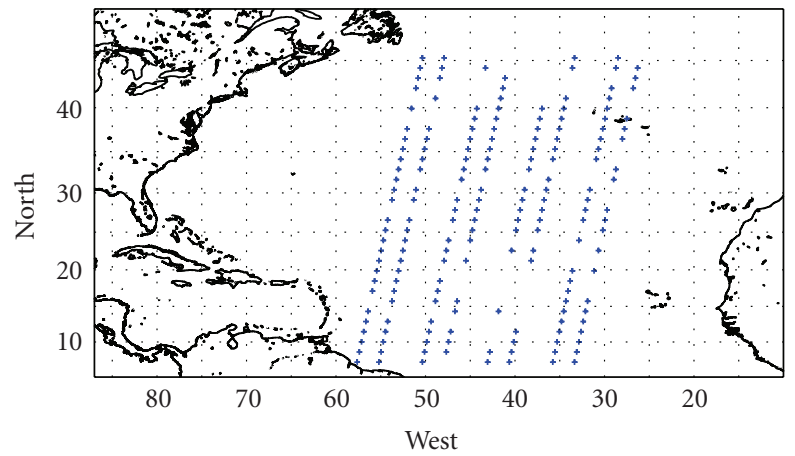

(c)

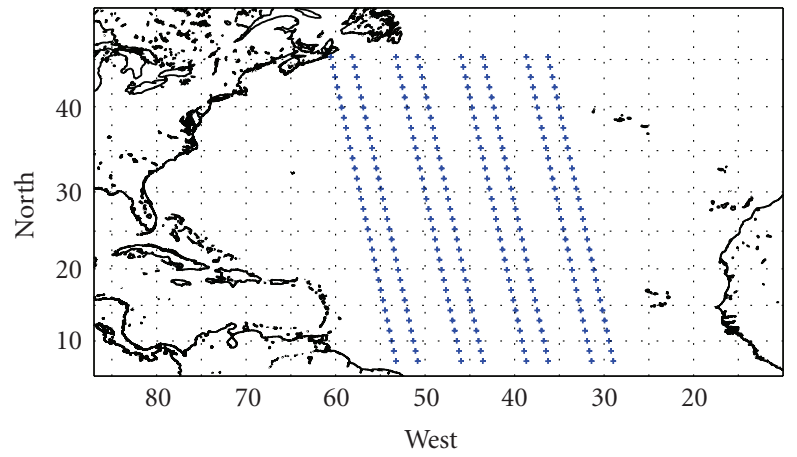

(b)

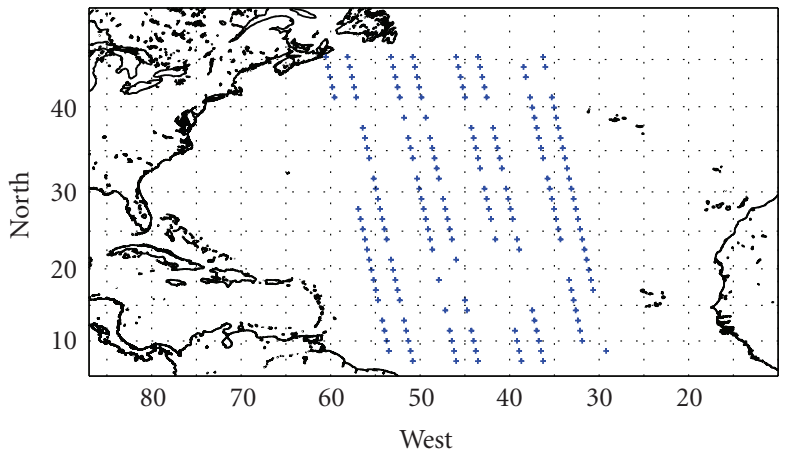

(d)

Figure 1: Simulated DWL observation locations at 0600 UTC ((a) and (c)) and 1800 UTC 01 October 2005 ((b) and (d)). (a), (b), (c), and (d) are simulated observation sampling for data assimilation Experiment 1 and Experiment 2, respectively.

reanalysis, which is processed by a much lower resolution model.

Since we intend to evaluate the data impact on tropical cyclone forecasts with a mesoscale model, we choose to use the T799 NR. From the T799 NR, a tropical storm, which occurred over the Atlantic Ocean during the period from 27 September to 11 October 2005, was arbitrarily selected for this study. The simulation period is from 0600 UTC 01 to 0600 UTC 03 October 2005.

3.2. Experimental Design. A two-way nested interactive simulation was conducted for all experiments. The model horizontal resolutions were $27 \mathrm{~km}$ for outer domain and $9 \mathrm{~km}$ for inner domain, respectively. In total there were 31 vertical model levels from the surface up to $50 \mathrm{hPa}$. Various model physics options were used in the different experiments.

Four experiments were conducted:

(i) a regional nature run to generate the "truth" field;

(ii) a control run to generate a reference field;

(iii) two data assimilation experiments with different observational sampling strategies to investigate the potential impact of the simulated DWL wind profiles on the storm track and intensity forecasts. Results were compared against the regional nature run and control run.
Differences in the model setups and configurations for all above experiments are summarized in Table 1.

3.2.1. Regional Nature Run. In this paper, we mainly focus on the regional numerical model prediction problems. $\mathrm{Pu}$ et al. [28] has commented that the ECMWF nature runs are sufficiently accurate in describing the tropical cyclone track and intensity at an intermediate model resolution. However, they are not good enough in representing the tropical cyclone inner-core structures. Thus, it is necessary to generate regional nature runs for regional verification purposes. In this study, the WRF model was nested inside of the ECMWF nature run to generate a set of regional nature runs. The model was initialized using the T799 NR and then integrated forward for 78 hours starting at 0000 UTC 30 September 2005. The domain sizes are $377 \times 259$ and $646 \times 583$ for the outer and inner domain, respectively. The horizontal grid spacing is $27 \mathrm{~km}$ for the outer domain and $9 \mathrm{~km}$ for the inner domain, respectively, as mentioned above. The model physics parameterizations include: the Lin microphysics scheme, Mellor-Yamada-Janjic planetary boundary layer model (MYJ), Betts-Miller-Janjic cumulus parameterization scheme, RRTM longwave, and Dudhia shortwave radiation model. Detailed descriptions of each physical parameterization scheme can be found in Skamarock et al. [29]. 


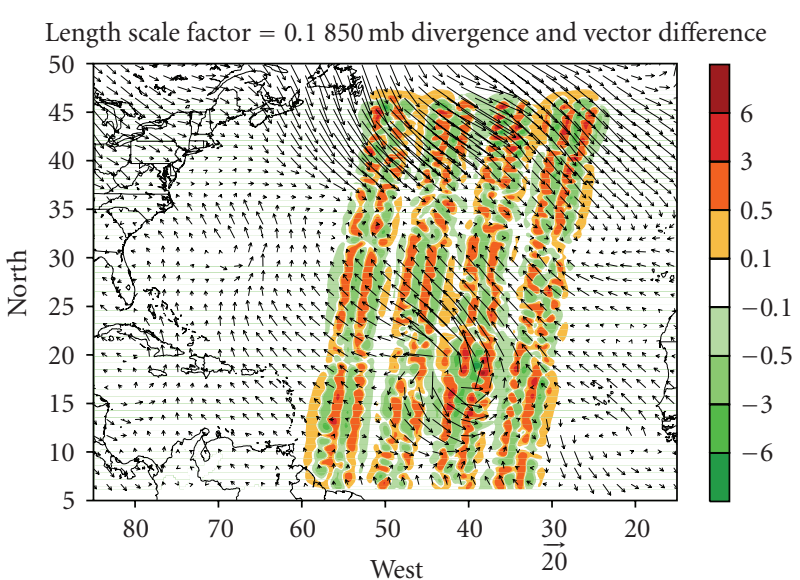

(a)

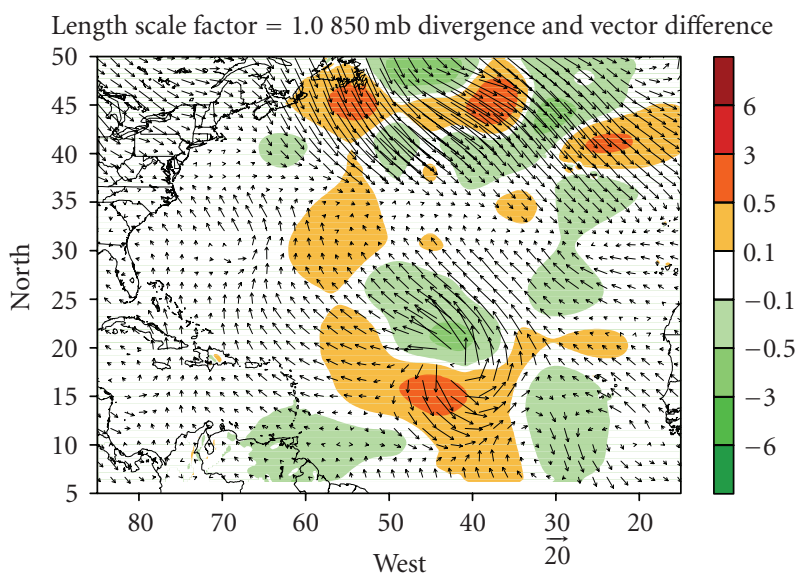

(c)

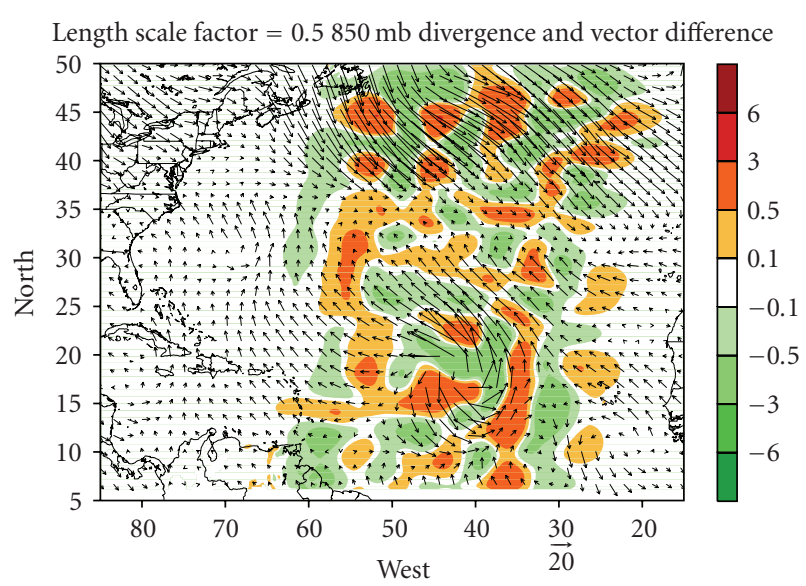

(b)

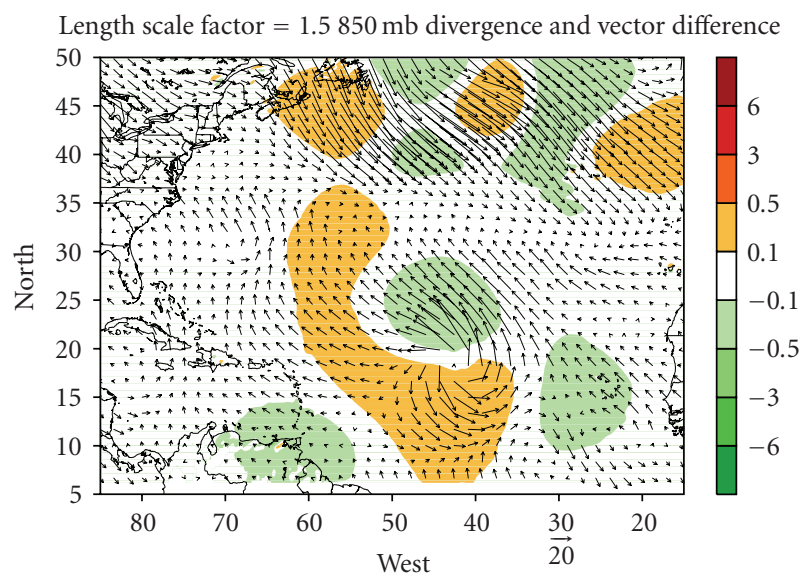

(d)

FIgURE 2: Horizontal wind and divergence increments at $850 \mathrm{hPa}$ for length scale factor of 0.1 (a), 0.5 (b), 1.0 (c), and 1.5 (d) at $0600 \mathrm{UTC}$ 01 October 2005.

TABLE 1: Summary of model set up for all experiments.

\begin{tabular}{|c|c|c|c|c|c|}
\hline & & Regional nature run & Control run & DA Exp1 & DA Exp2 \\
\hline \multirow{3}{*}{\multicolumn{2}{|c|}{ Time period }} & 00Z 30 September & 06Z 01 October & 06Z 01 October & 06Z 01 October \\
\hline & & 2005-00 Z 05 October & 2005-06Z 03 October & 2005-06Z 03 October & 2005-06Z 03 October \\
\hline & & 2005 & 2005 & 2005 & 2005 \\
\hline \multirow[t]{3}{*}{ Size of domain } & & $377 \times 259$ & $307 \times 217$ & $307 \times 217$ & $307 \times 217$ \\
\hline & & $646 \times 583$ & $406 \times 349$ & $406 \times 349$ & $406 \times 349$ \\
\hline & Microphysics scheme & Lin & WSM-6 & WSM-6 & WSM-6 \\
\hline \multirow[t]{2}{*}{ Physics scheme } & PBL scheme & MYJ & YSU & YSU & YSU \\
\hline & Cumulus scheme & Betts-Miller & Grell & Grell & Grell \\
\hline \multirow[t]{2}{*}{ Initialization } & $\begin{array}{l}\text { Initial / first guess } \\
\text { fields }\end{array}$ & T799 NR & T511 NR & T511 NR & T511 NR \\
\hline & Boundary conditions & T799 NR & T799 NR & T799 NR & T799 NR \\
\hline
\end{tabular}

3.2.2. Control Run. The control run was a 48-hour free forecast. Unlike the regional nature run, the model integration started at 0600 UTC 01 October 2005, instead of at 0000 UTC 30 September in the regional nature run, and ended at 0600 UTC 03 October 2005. The initial conditions were obtained by interpolating the ECMWF coarser resolution T511 NR into the WRF model domains. The boundary conditions were provided by the T799 NR. The model domains were set within the domains of the regional nature run but were smaller in size. The domain sizes were $307 \times 217$ and $406 \times 349$ for the outer and inner domains, respectively. In order to take into account the model errors in OSSEs, model physics options that were deployed in the control run were different from these used in the regional nature 


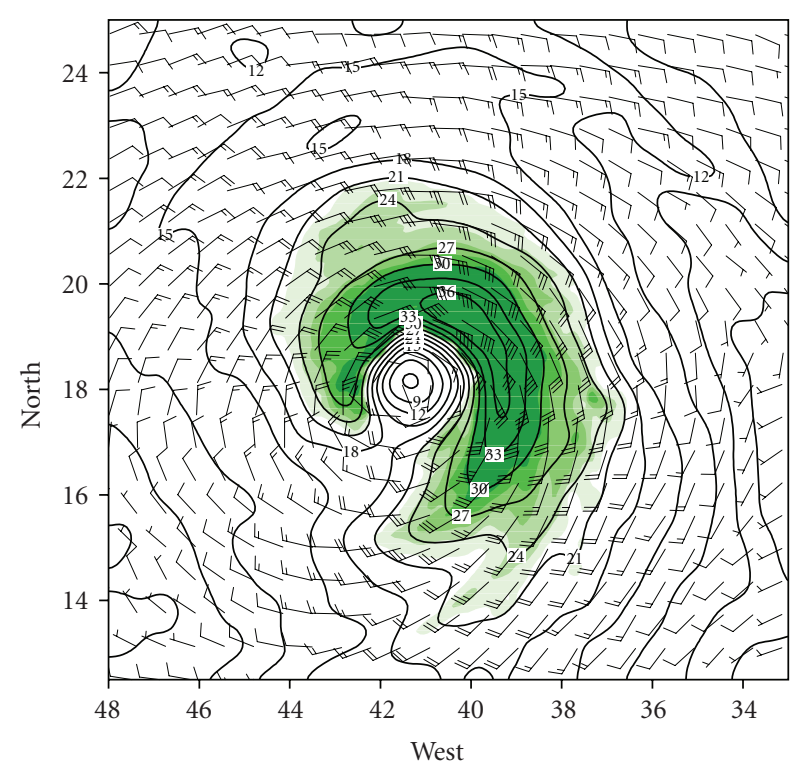

(a)

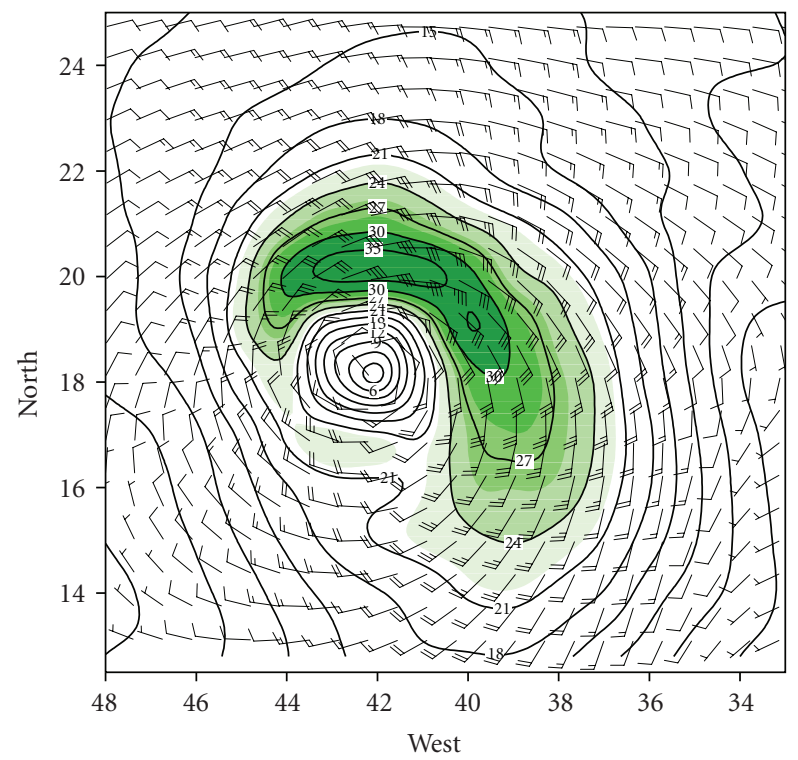

(c)

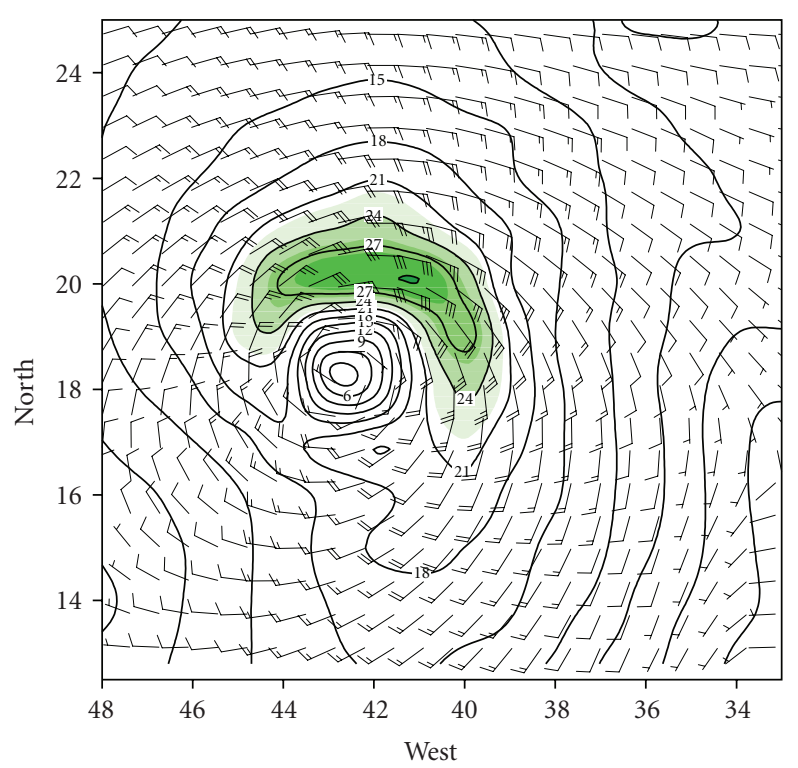

(b)

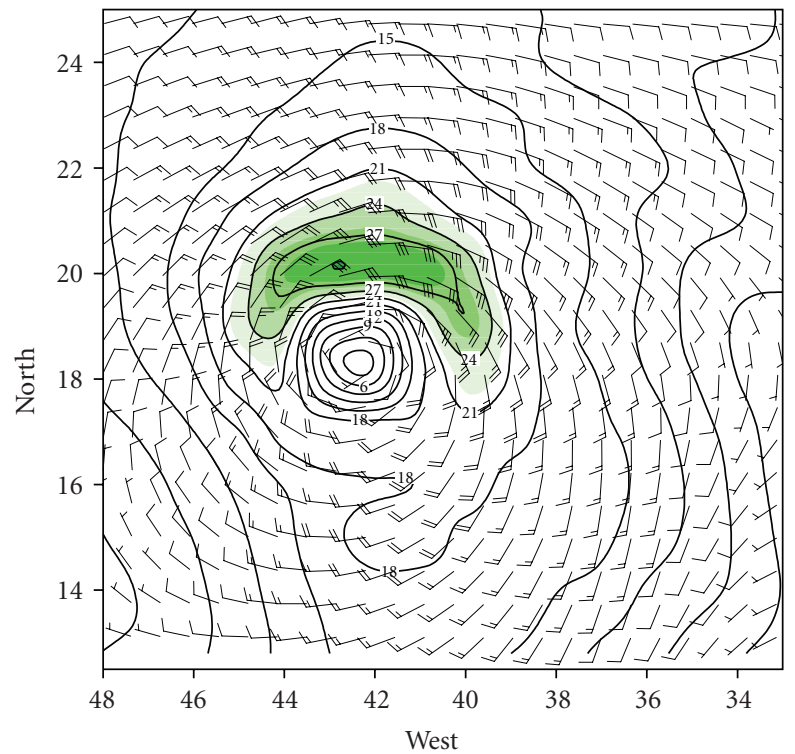

(d)

FIgURE 3: Horizontal wind structure (wind speed contour and wind vector) at the storm center at 850 hPa from (a) regional nature run, (b) control run, (c) data assimilation Experiment 1, and (d) data assimilation Experiment 2 at 0600 UTC 01 October 2005. The contour interval of wind speed is $3 \mathrm{~m} \mathrm{~s}^{-1}$, the areas with wind speed exceeding $20 \mathrm{~m} \mathrm{~s}^{-1}$ are shaded.

run. Thus, the physics options include: the WRF SingleMoment 6-class microphysics scheme (WSM-6), the Yonsei University planetary boundary layer model (YSU PBL), and the Grell-Devenyi ensemble cumulus parameterization scheme. Other parameters are same as in the regional nature run.

3.2.3. Simulation of Observations. According to Marseille et al. $[12,13]$, the DWL was assumed to be aboard on a given polar-orbiting satellite. This means that the wind measurements are available only twice daily over the same region. An idealized distribution of observations is used following an early suggestion from D. Emmitt (personal communication). Considering the influence of clouds, two configurations of the observations sampling are simulated. Figures 1(a) and 1(b) show the distributions of the simulated DWL observations in data assimilation Experiment 1 (DA Exp1) at 0600 UTC and 1800 UTC 01 October 2005, respectively. In this observational configuration, cloud effect is not taken into account. Wind observations are available from near the surface up to $18 \mathrm{~km}$. To simulate the DWL sampling in cloudy atmospheres, we used the realistic atmospheric conditions extracted from the regional nature run dataset. Figures $1(\mathrm{c})$ and $1(\mathrm{~d})$ represent the simulated observation 


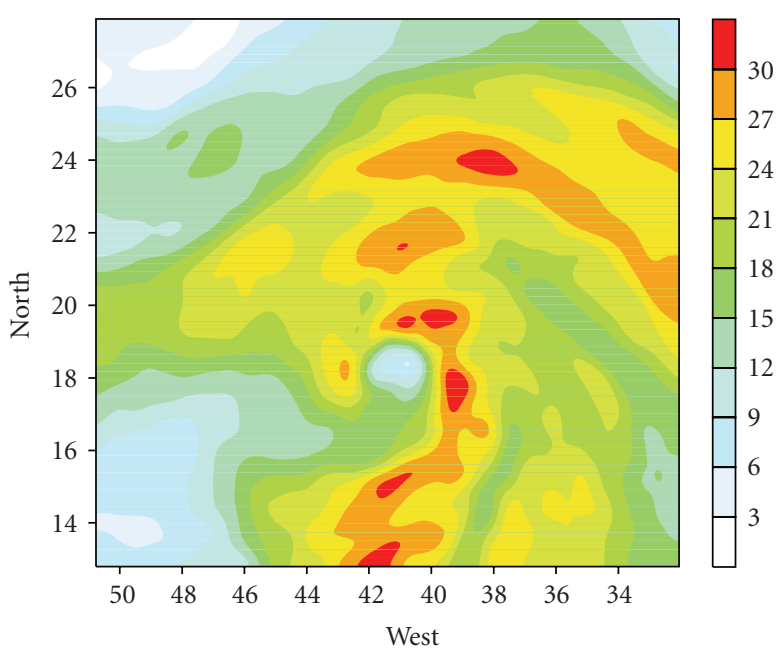

(a)

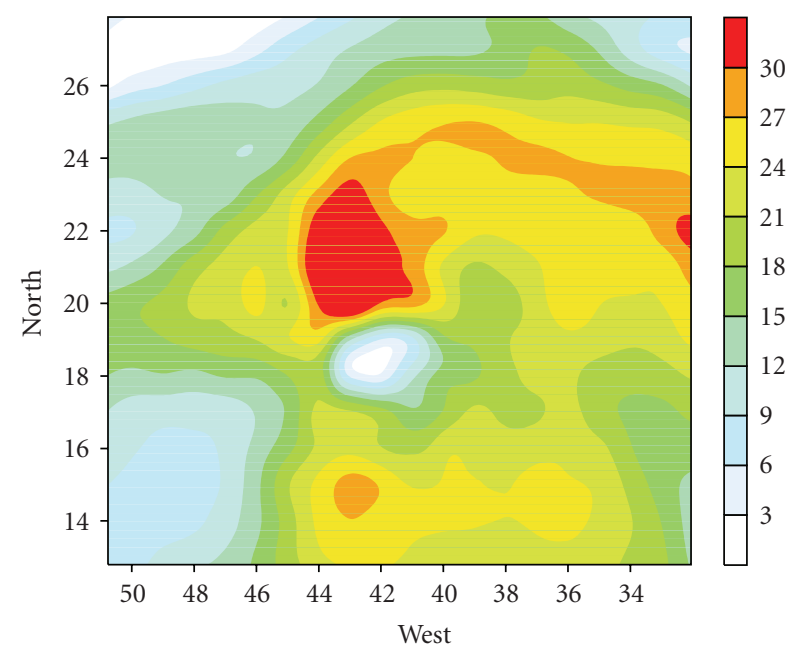

(c)

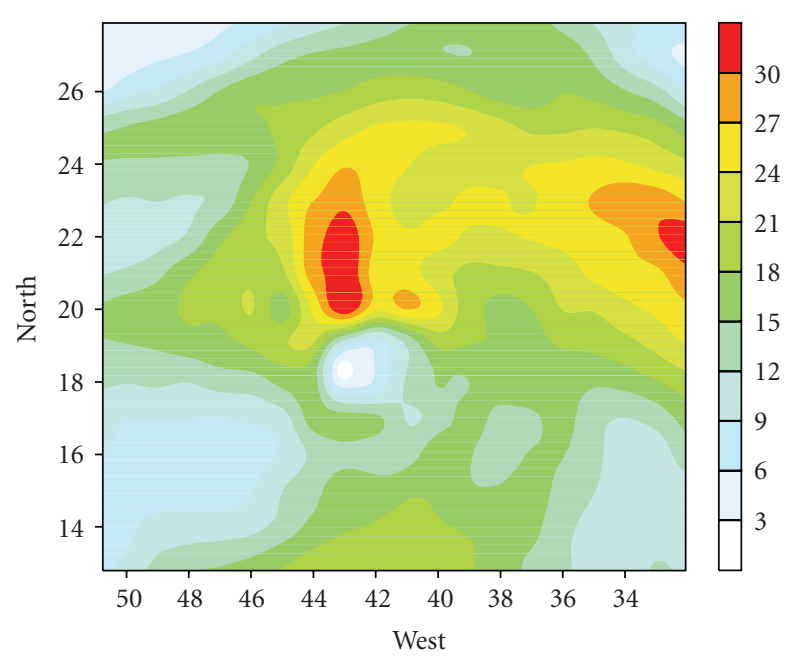

(b)

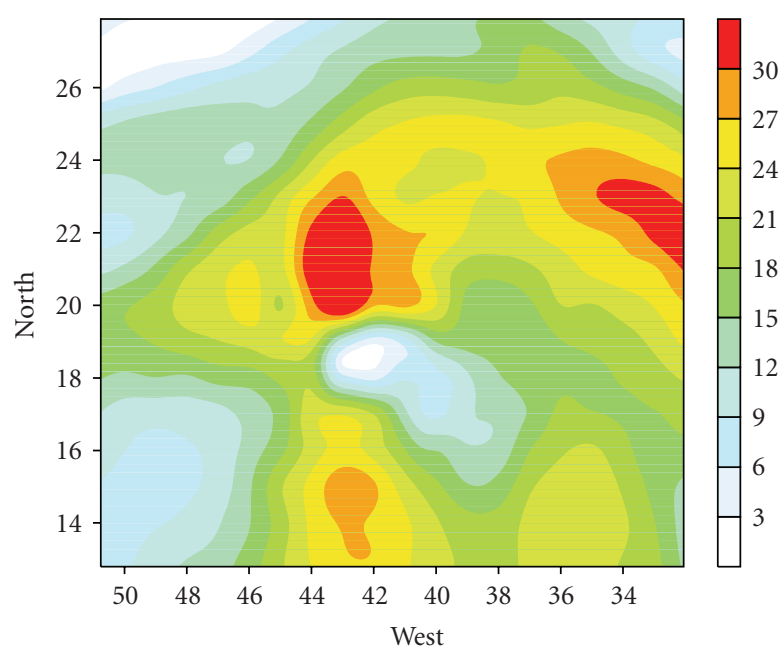

(d)

Figure 4: The wind shear (units: $\mathrm{m} \mathrm{s}^{-1}$ ) between $850 \mathrm{hPa}$ and $200 \mathrm{hPa}$ at $0600 \mathrm{UTC} 01$ October 2005 from (a) regional nature run, (b) control run, (c) data assimilation Experiment 1, and (d) data assimilation Experiment 2.

configurations with consideration of the cloud effect and are used in data assimilation Experiment 2 (DA Exp2). Since the cloud effect is taken into account in this case, wind profiles are not available in areas with cloud contamination. In both DA Exp1 and DA Exp2, the observations used for data assimilation experiments are generated by interpolating the "truth" field (regional nature run) both horizontally and vertically from the model grids onto the simulated observational locations and by superimposing random noises. The vertical resolution of the measurements is $250 \mathrm{~m}$ below and $1 \mathrm{~km}$ above the $2 \mathrm{~km}$ level. Typical values for the standard deviation of DWL wind errors are $2 \mathrm{~m} \mathrm{~s}^{-1}$ below $2 \mathrm{~km}$ and $3 \mathrm{~m} \mathrm{~s}^{-1}$ above the $2 \mathrm{~km}$ level [30]. No bias has been assumed for the simulated DWL wind errors.

3.2.4. Data Assimilation Experiments. The WRF 3DVAR system was used to assimilate DWL wind profiles. Corresponding to the two configurations of the simulated observations mentioned in Section 3.2.3, two data assimilation experiments are performed: the first is an ideal experiment that does not consider cloud influence. The observational samplings are shown in Figures 1(a) and 1(b) for 0600 UTC and 1800 UTC, respectively. For simplification, in this paper it is referred as DA Exp1. The other one is a more realistic experiment. As shown in Figures 1(c) (for 0600 UTC) and 1(d) (for 1800 UTC), the observations contaminated by clouds are eliminated. For simplification it is referred as DA Exp2. Similar to the control run, the model domain configuration and physics options for both of these two experiments are the same as those used in the control run. The first guess field was initialized at 0600 UTC 01 October 2005 from the T511 NR. A cycled data assimilation was carried out to assimilate simulated DWL wind profiles between 0600 UTC and 1800 UTC 01 October 2005. The data assimilation was conducted between 0600 UTC 01 October 2005 and 1800 UTC 01 October 2005. After that, the model 


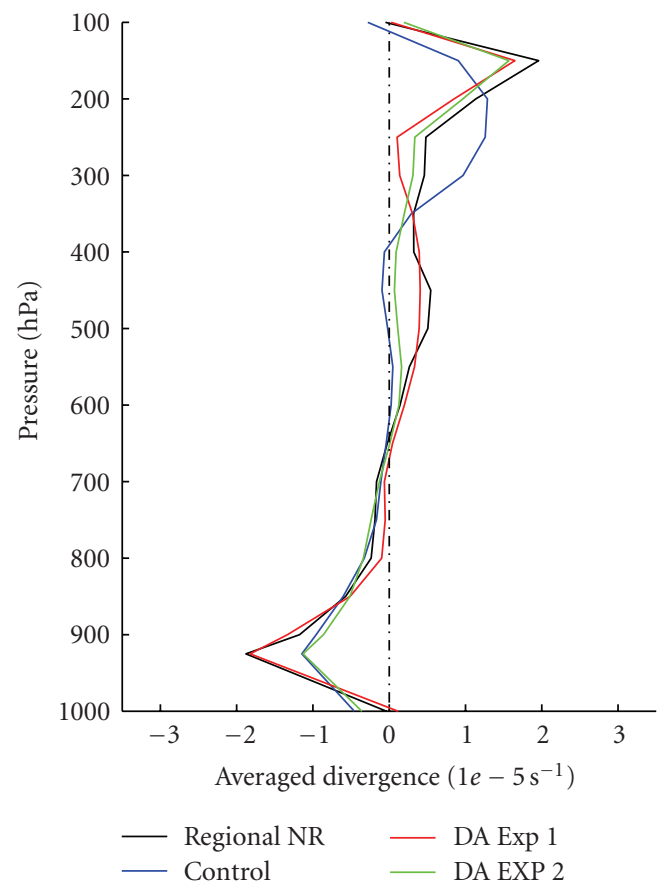

FIgURE 5: Area-averaged divergence vertical profiles over the area with radius of $250 \mathrm{~km}$ around the storm center at 0600 UTC 01 October 2005 (black line: regional nature run; blue line: control run; red line: data assimilation Experiment 1; green line: data assimilation Experiment 2).

initial condition was replaced by the analysis from data assimilation experiments and then a 36-hour forecast was conducted from 1800 UTC 01 October to 0600 UTC 03 October 2005. All results presented in this paper use the results from the $9 \mathrm{~km}$ grid domain.

\section{Results and Discussion}

4.1. Sensitivity of DWL Data Assimilation to Background Error Correlations. The basic goal of the 3DVAR is to find an optimal estimate of the model initial conditions at analysis time through the minimization of a cost function $J$ :

$$
\begin{gathered}
J=J_{b}+J_{o}, \\
J_{b}=\frac{1}{2}\left(x-x_{b}\right)^{T} \mathbf{B}^{-1}\left(x-x_{b}\right), \\
J_{o}=\frac{1}{2}\left(H(x)-y_{o}\right)^{T} \mathbf{O}^{-1}\left(H(x)-y_{o}\right) .
\end{gathered}
$$

The cost function $J$ is a combination of a background term $J_{b}$ and an observation term $J_{o}(1)$. Here $J_{b}$ is the background term that measures the distance between analysis and background (2), $J_{o}$ is the observation term that measures the distance between observations and model-simulated observations (3). The superscripts -1 and $\mathrm{T}$ denote the inverse and adjoint of a matrix or a linear operator, respectively. $\mathbf{B}$ is the background error covariance matrix. In this study, the $\mathbf{B}$

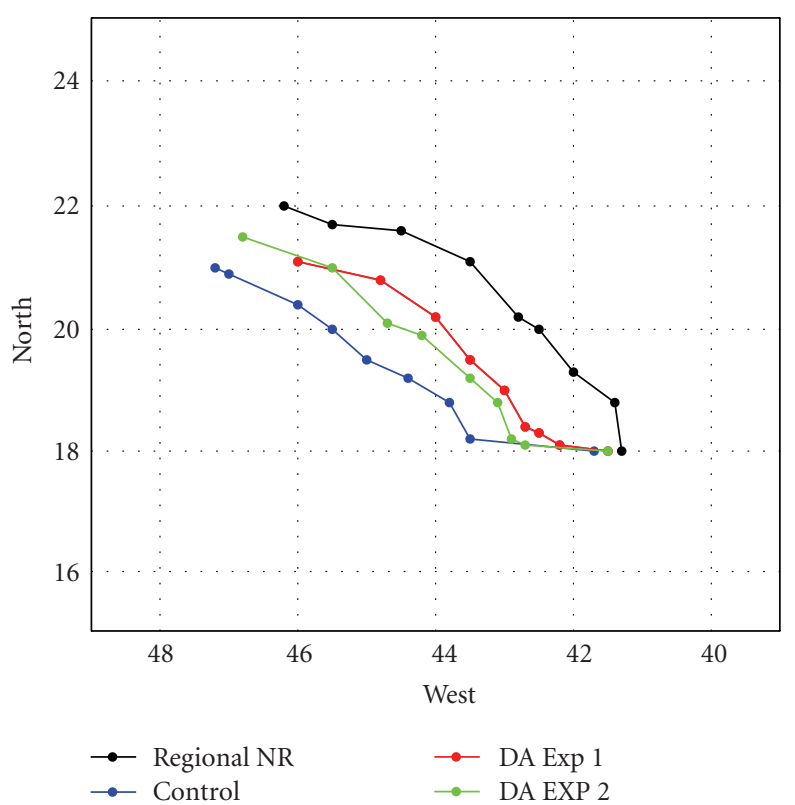

(a)

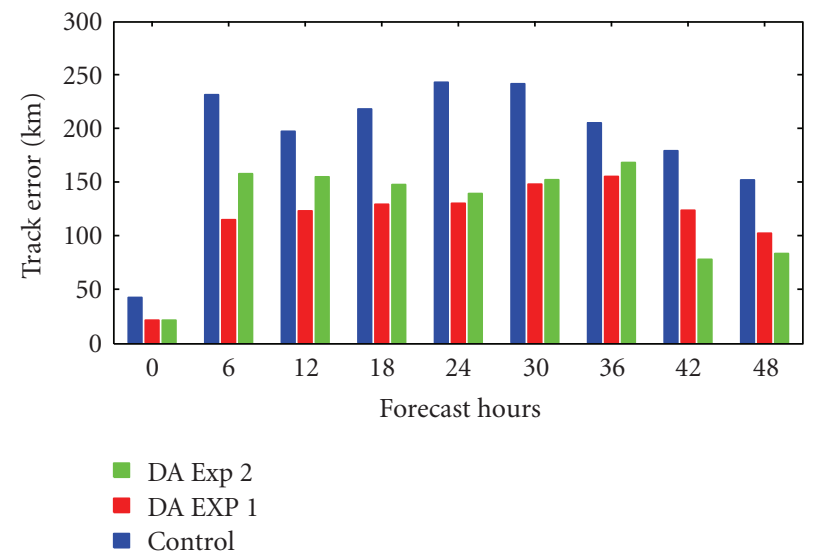

(b)

Figure 6: Time series of the tropical cyclone (a) track and (b) track error during 48-hour simulations for different experiments (black line: regional nature run; blue line: control run; red line: data assimilation Experiment 1; green line: data assimilation Experiment 2) from 0600 UTC 01 to 0600 UTC 03 October 2005.

matrix was generated using the NMC-method [23], which is a popular method used for background error estimation. $\mathbf{O}$ is the observation error covariance matrix. $x_{b}$ is the first guess field, usually it is a short-range forecast or from an analysis. $H$ is the observation operator that transforms model variables from model physical space to the observation space. $y_{o}$ is the observation at the analysis time.

The background error covariance matrix (B matrix) plays an important role in a 3DVAR system. It influences the analysis fit to observations and also define the influencing distance of the analysis response from the observations. In the horizontal direction, the background error correlations are assumed to be a Gaussian probability density function (4). The observational information is spread using a 


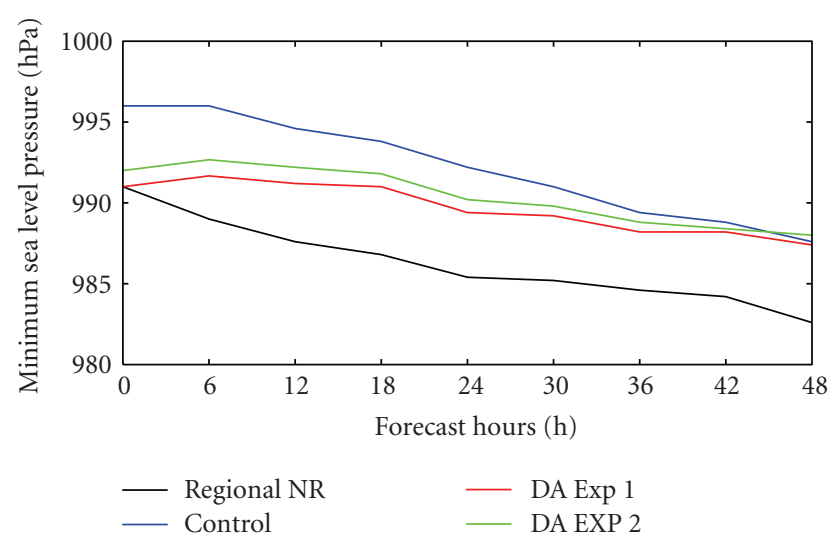

(a)

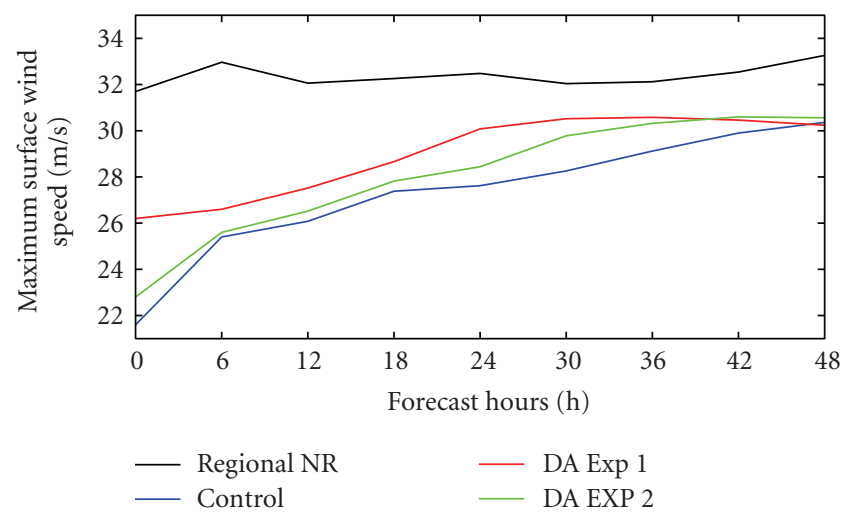

(b)

Figure 7: Time series of (a) minimum Sea Level Pressure (SLP) at the storm center and (b) maximum surface wind speed from different experiments (black line: regional nature run; blue line: control run; red line: data assimilation Experiment 1; green line: data assimilation Experiment 2) from 0600 UTC 01 to 0600 UTC 03 October 2005.

recursive filter, while the vertical relation is represented by applying the empirical orthogonal decomposition technique:

$$
B(r)=B(0) \exp \left(-\frac{r^{2}}{s^{2}}\right)
$$

In (4), $r$ is the distance between the model grid point and the observation location, $s$ is the length scale of the Gaussian function, and it determines how far the observation information can be spread spatially. $B(0)$ is the background covariance at observation location and $B(r)$ is the background error covariance at the model grid point away from the observation location with distance $r$.

Since the B matrix is based on climatological statistics, in order to specify it for the DWL data and grid resolution used in this particular study, four experiments were conducted to examine the impact of different length scales on the analysis results of wind fields where the length scales were set to $0.1,0.51 .0$, and 1.5 times of the original values (which uses statistics from the NMC method). The data assimilated in all of these four experiments are the DWL wind profiles from Figure 1(a). Figure 2 shows the horizontal wind vectors and divergence increments (i.e., 3DVAR analysis minus first guess) from these four experiments at $850 \mathrm{hPa}$ at analysis time 0600 UTC 01 October 2005. It shows that the horizontal distributions of the analysis increments from assimilation of DWL data were significantly different among these four experiments. If a small length scale (such as 0.1 times of the original values) was used, the observations only influenced the areas surrounding its locations. This implies that, in this situation, the observation information cannot be used optimally and that areas far away from the observation locations cannot benefit from the observations. If a large length scale (such as 1.5 times of the original values) was employed, although the observation information was spread to the areas far away from the observation locations, the relations were not always realistic for practical applications. Therefore, in practical applications, determining a reasonable horizontal correlation length scale for various kinds of observations, model resolutions, and observation density is still a challengeable question for a 3DVAR method. Comparing the analysis results from all four experiments, a length scale of 1.0 seems to be optimal for the analysis of the DWL data in this study. Therefore, a length scale factor of 1.0 was adapted for all experiments.

\subsection{Data Impact on Initial Conditions}

4.2.1. Horizontal Wind Structures. Figure 3 shows the horizontal winds at $850 \mathrm{hPa}$ from the regional nature run, the control run, DA Exp1, and DA Exp2 at 0600 UTC 01 October 2005, respectively. In Figure 3, the shaded areas indicate regions with wind speed exceeding $20 \mathrm{~m} \mathrm{~s}^{-1}$. Compared with the regional nature run simulation, both the control run and data assimilation experiments are able to reproduce the basic structures of the storm wind field. However, the simulated wind speed from the control run was weaker than that from the data assimilation experiments. After data assimilation, a more intensive wind structure was found near the storm center. In DA Exp1, the wind field in the southeast of the storm center was strengthened and the location of the regions with wind speed exceeding $20 \mathrm{~m} \mathrm{~s}^{-1}$ agreed well with the regional nature simulation. The maximum surface wind speed near the storm center reached $26.3 \mathrm{~m} \mathrm{~s}^{-1}$. This indicates that assimilation of DWL wind profiles enhanced the wind field around storm center. In DA Exp2, the wind field around the storm center was not enhanced as in DA Exp1. This could be mainly attributed to the fact that there are fewer observations available over the storm center in DA Exp2.

4.2.2. Wind Shear. Wind shear, which is the change in wind speed or direction with height in the atmosphere, is one of the most critical factors controlling tropical cyclone formation and destruction [31]. Figure 4 illustrate the wind shear between $850 \mathrm{hPa}$ and $200 \mathrm{hPa}$ at 0600 UTC 01 October 2005 from the regional nature run, the control run, DA Exp1 and DA Exp2, respectively. The wind shear structures 


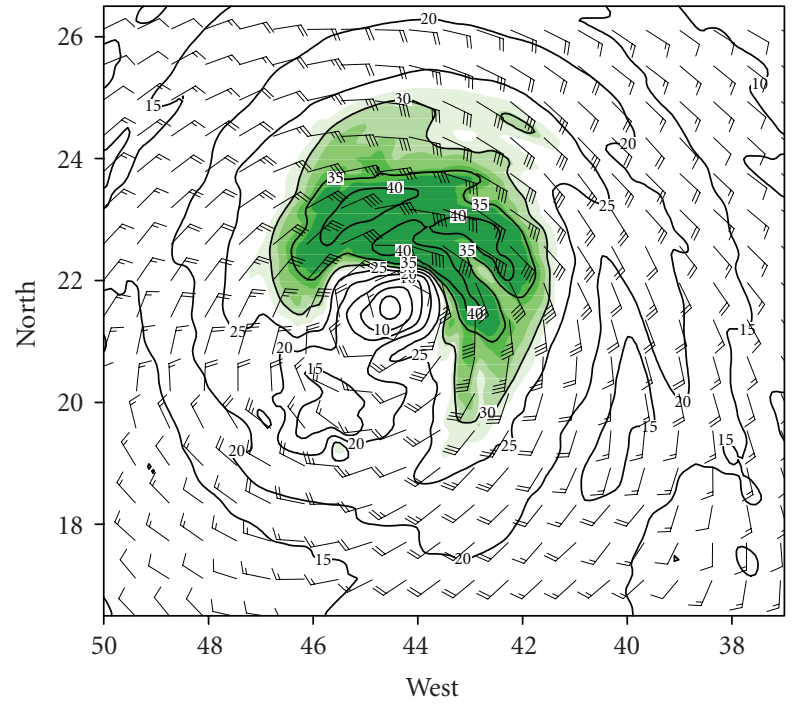

(a)

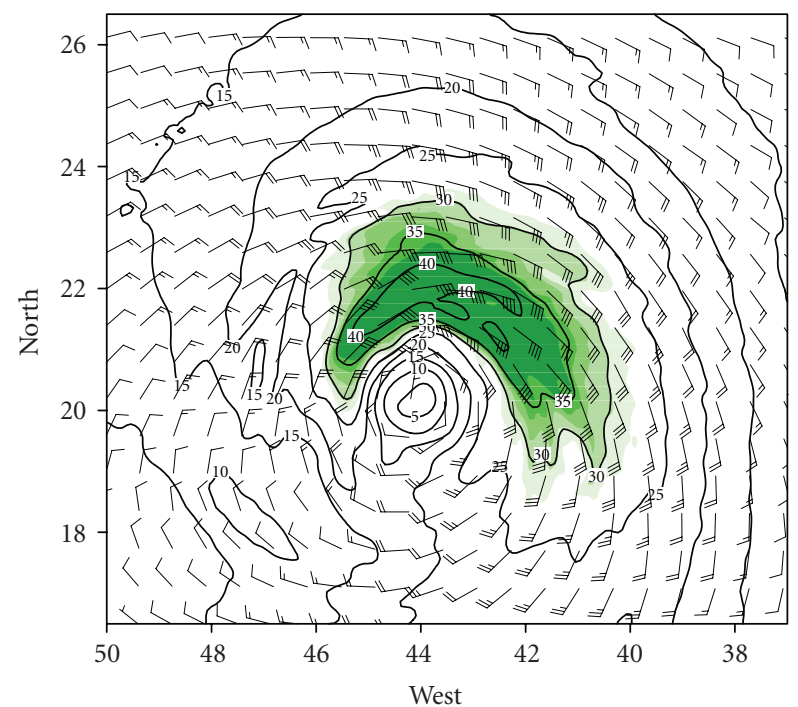

(c)

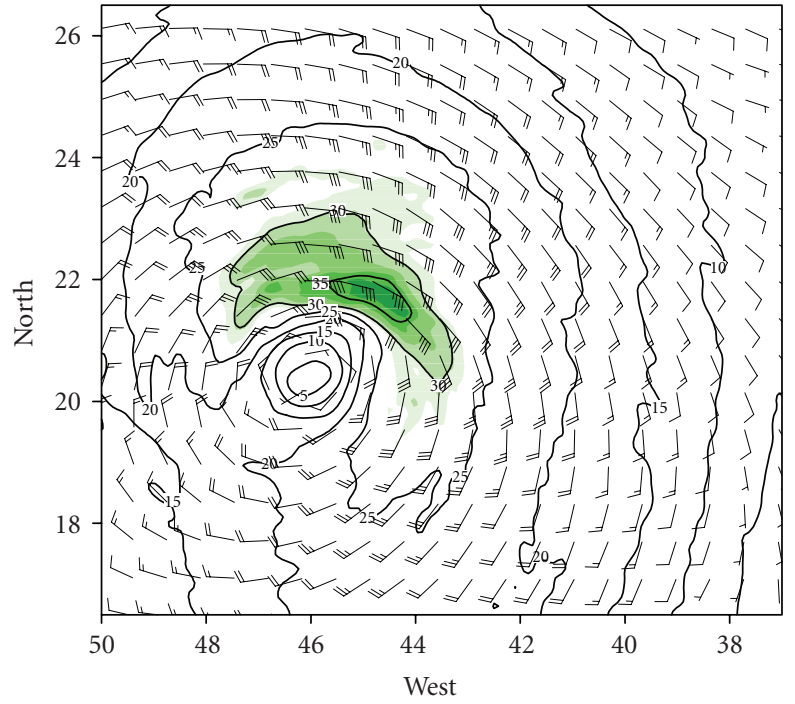

(b)

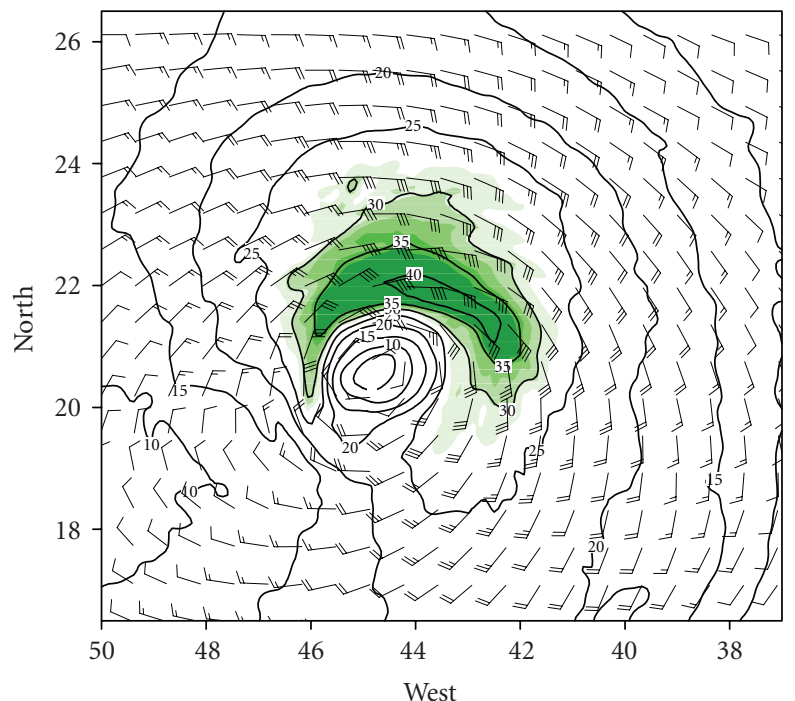

(d)

Figure 8: Same as Figure 3 but at 1800 UTC 02 October 2005. The contour interval of wind speed is $5 \mathrm{~m} \mathrm{~s}^{-1}$, the areas with wind speed exceeding $26 \mathrm{~m} \mathrm{~s}^{-1}$ are shaded.

were well reproduced after assimilating DWL wind profiles as simulated structural features was much closer to that of the regional nature run. In both the control run and data assimilation experiments, the simulated maximum wind shear appears in the north of the storm center. It is a little farther to the west compared to the regional nature run. But in the control run, in the south of the storm center the wind shear from the control run was weaker than those from DA Exp1 and DA Exp2. This indicates that assimilation of 3D wind profiles has the potential to adjust the vertical structures of the wind field to some extent. In addition, since the observations over the storm center were available and were assimilated in DA Exp1, the structure of the wind shear around the storm center is much closer to that of the regional nature run, compared with the DA Exp2 analysis results.
4.2.3. Divergence Fields. Figure 5 shows the area-averaged divergence vertical profiles within a radius of $250 \mathrm{~km}$ around the storm center for these four experiments at 0600 UTC 01 October 2005. Compared to the results from the data assimilation experiments, in the control run, the divergence variation with height showed a larger difference from the regional nature run simulation. For data assimilation experiments, in DA Exp1, from the surface to $400 \mathrm{hPa}$, the area-averaged divergence was very close to that of the regional nature run; above $400 \mathrm{hPa}$, the divergence profile did not keep close to the nature run simulations. But, it kept the same tendency. DA Exp2 did not behave as good as DA Exp1, but it still performed better than the control run. A possible explanation for this is the fact that more observations over the storm center were included in DA Exp1. 


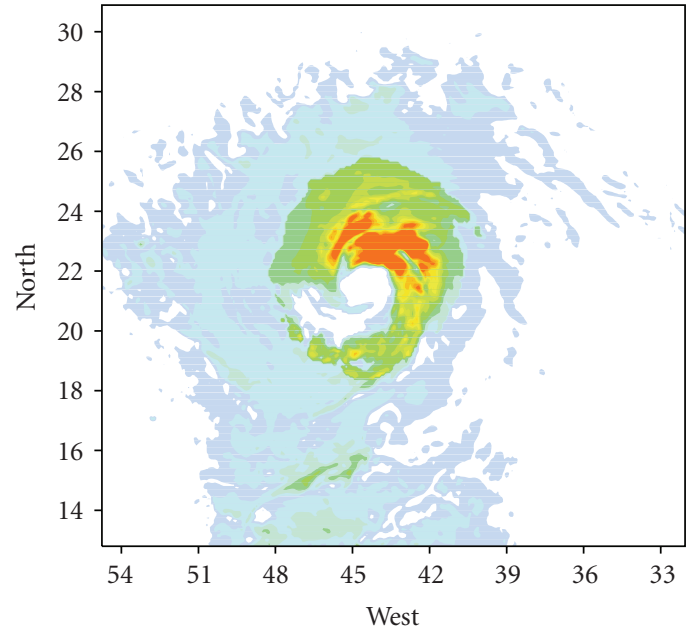

(a)

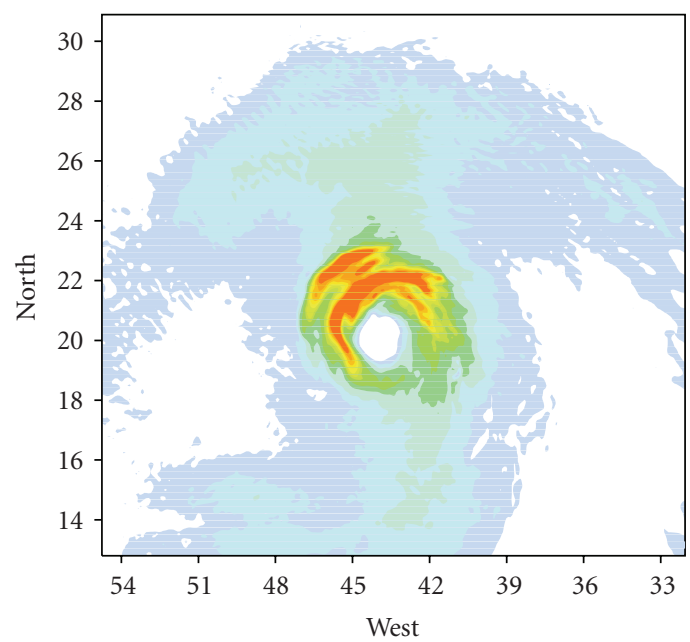

(c)
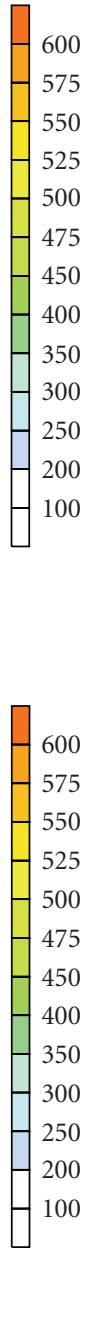

.

Figure 9: The surface latent heat flux $\left(\mathrm{W} \mathrm{m}^{-1}\right)$ from (a) regional nature run, (b) control run, (c) data assimilation Experiment 1, and (d) data assimilation Experiment 2 at 1800 UTC 02 October 2005.

\subsection{Impact on Forecasts}

4.3.1. Track and Intensity. Figures 6 and 7 show the time evolution of the simulated track and minimum central sea level pressure (SLP) and maximum surface wind speed for different experiments.

From Figure 6, the simulated storm track in the control run was farther to the west and the storm moved slightly quicker compared to the regional nature run. After assimilating the DWL 3D wind profiles, the storm track forecast was improved and the predicted storm track error was reduced compared to the control run. Compared with the results from DA Exp2, the simulated storm track in DA Exp 1 is much closer to the nature run simulations ("truth") in the first 24-h simulation. The track errors are smaller than those from DA Exp2. The advantages from DA Exp1 can be attributed to including the observations over cloudy areas (most of them over the storm center). After 36

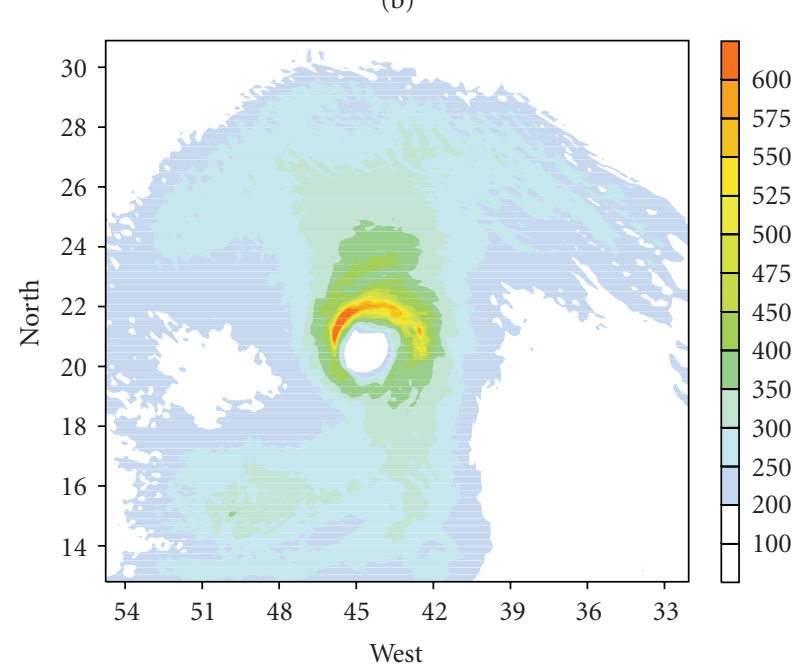

(d)

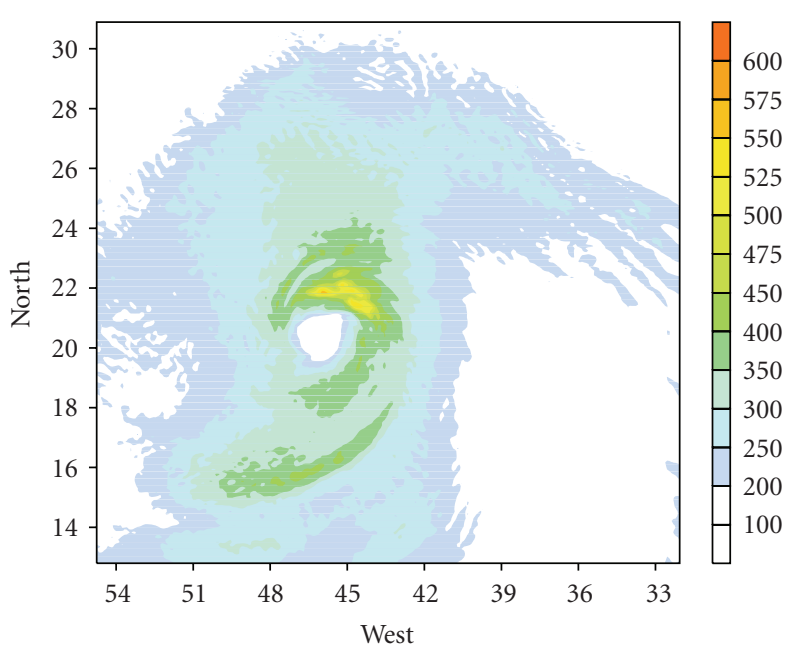

(b) hours simulation, the DA Exp2 performed better in track simulation.

In the regional nature run ("truth"), the minimum central SLP was $991 \mathrm{hPa}$ and steadily dropped to $983 \mathrm{hPa}$ within the first 36-hour simulation. It then deepened slowly during the following 12 hours (Figure 7). Accordingly, the maximum surface wind intensified gradually in the first 36 hours and then increased slowly in the following 12 hours. The simulated minimum central SLP of the storm from the control run showed the same tendency during the 48-hour simulation but it was weaker than that from the regional nature run. The maximum surface wind was also weaker than that from the regional nature run. In DA Exp1, both the minimum SLP and the maximum surface wind were improved significantly during the first 36 hours, and then the improvements decreased slightly over the next 12 hours. In DA Exp2, the storm intensity was also improved after 


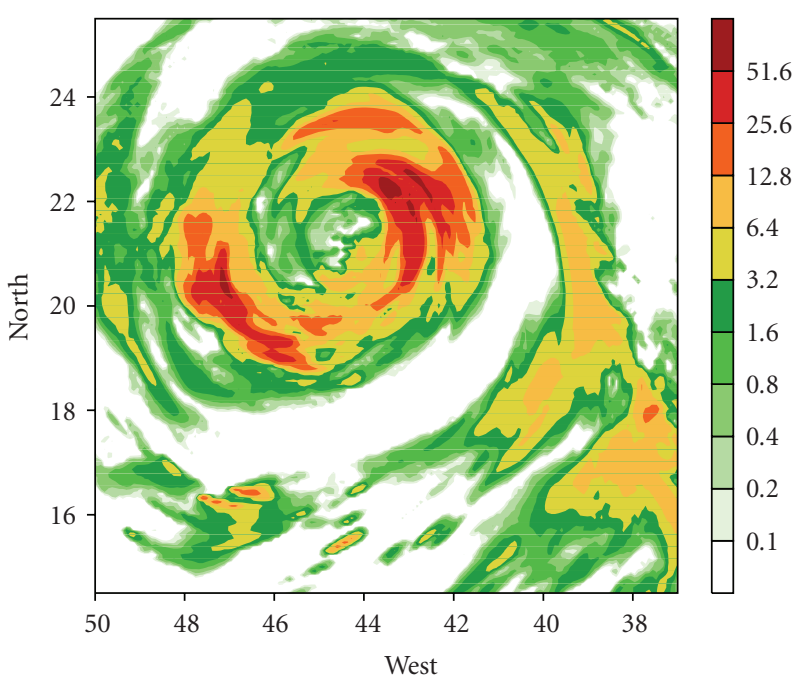

(a)

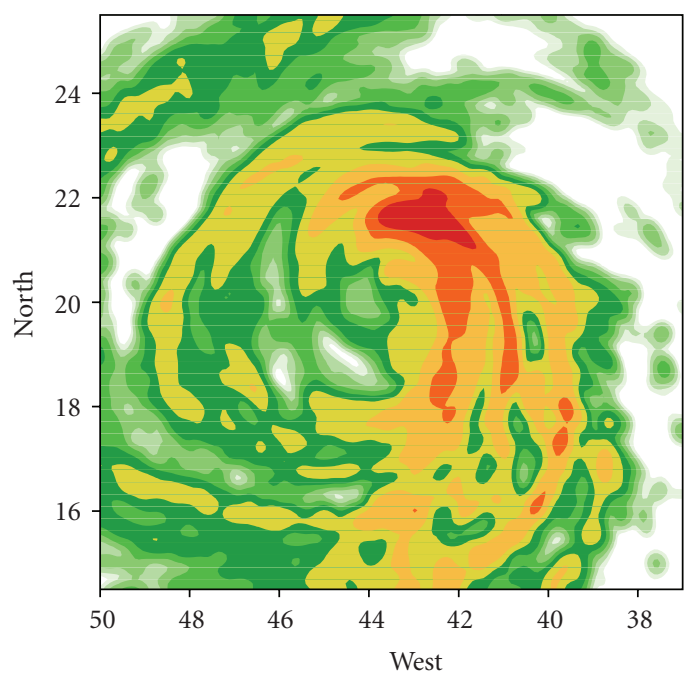

(c)

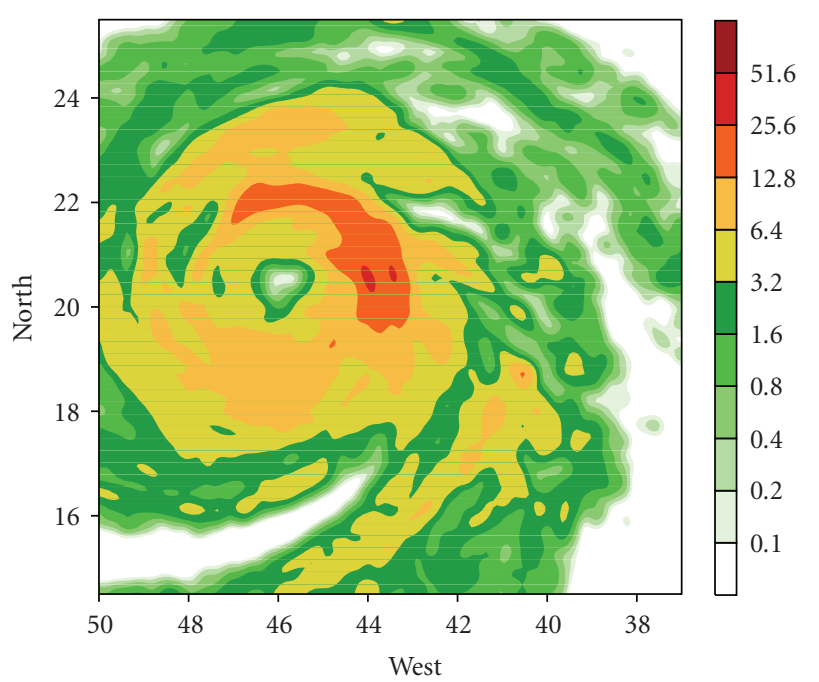

(b)

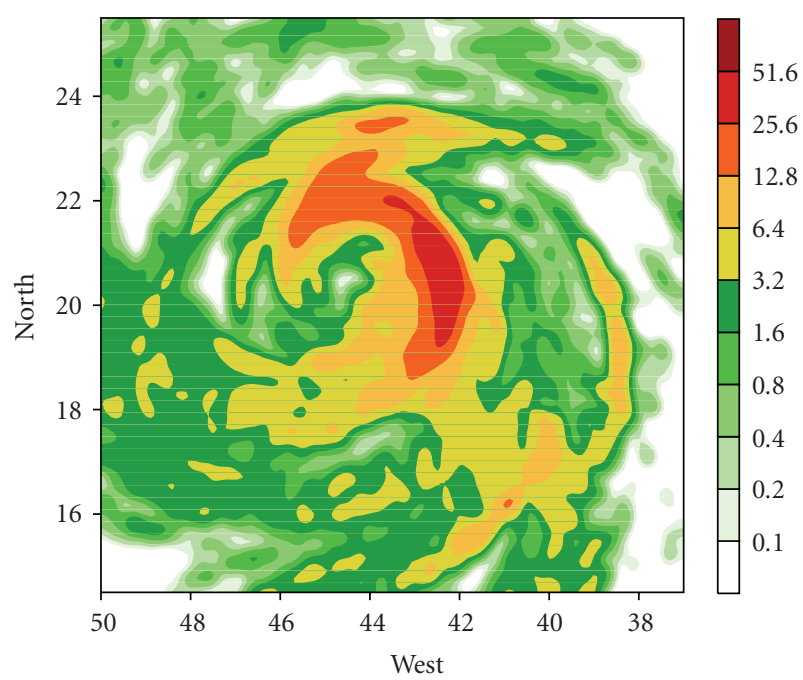

(d)

FIGURE 10: The simulated accumulated 3 hours rainfall ( $\mathrm{mm}$ ) from (a) regional nature run, (b) control run, (c) data assimilation Experiment 1, and (d) data assimilation Experiment 2 at 1800 UTC 02 October 2005.

data assimilation, but the improvements were a little weaker compared to that of DA Exp1.

In order to further examine the impact of DWL data on the simulation and prediction of tropical cyclones, diagnoses were also conducted for several other parameters as follows.

4.3.2. Horizontal Wind Structures. As discussed in Section 4.2.1, assimilation of DWL wind profiles enhanced the wind field at the initial time. It also made improvements in the wind simulations during the following forecast period. Figure 8 is the same as Figure 3 but for 1800 UTC 02 October 2005 (36 hours forecast). The shaded areas indicate the regions with wind speed exceeding $26 \mathrm{~m} \mathrm{~s}^{-1}$. Although both the control run and data assimilation experiments are able to produce the basic structure of the horizontal wind field, the simulated locations of the storm center are different. In the control run, the simulated storm center was farther to the west compared with the regional nature run simulation. In the data assimilation experiments (DA Exp1 and DA Exp2), the simulated storm centers are much closer to these from the regional nature run. In addition, the simulated wind field in the control run was much weaker than those from the data assimilation experiments. Compared with the regional nature run simulation, the horizontal wind intensity was better represented after data assimilation.

4.3.3. Surface Latent Heat Fluxes. Surface latent heat flux is the flux of heat from the Earth's surface to the atmosphere that is, associated with evaporation or transportation of water from the surface and subsequent condensation of water vapor in the troposphere. The heating at low-levels from the surface can substantially modify the temperature field thereby enhancing or destroying the baroclinic environment. In addition, the latent heat release, derived from 


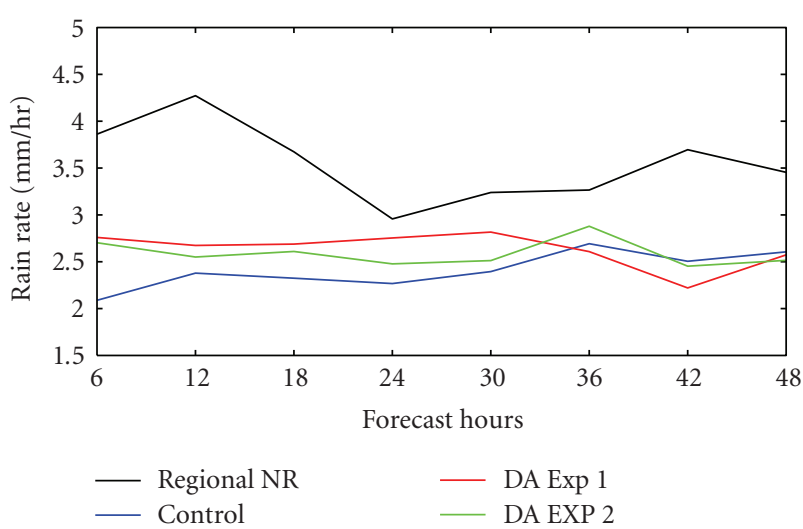

FiguRE 11: The time series of area-averaged rain rate $(\mathrm{mm} / \mathrm{hr})$ over the area with radius of $250 \mathrm{~km}$ around the storm center between 1200 UTC 01 and 0600 UTC 03 October 2005. (Black line: regional nature run; blue line: control run; red line: data assimilation Experiment 1; green line: data assimilation Experiment 2).

condensation throughout the troposphere can also be a crucial factor determining the vertical extent of the intense deepening of tropical cyclones. The influence of the latent heat flux over oceanic cyclones has been studied in many previous studies [32-36]. It was shown that the latent heat flux plays an important role in hurricane formation and intensification [15]. The study by Papasimakis et al. [37] indicates that hurricane development is heavily related to latent heat release. It was also pointed out that latent heat release had positive impacts on hurricane development and intensification. Figure 9 show the latent heat flux from these four experiments at 1800 UTC 02 October 2005. In the regional nature run (Figure 9(a)), the maximum latent heat release occurred mainly in the northeast of the storm center, while the simulated latent heat flux was too weak in the control run (Figure 9(b)). The locations of maximum latent heat flux in the data assimilation experiments are farther to the west of these from the regional nature run simulation; but the assimilations of the DWL wind profiles (Figures 9(c) and $9(\mathrm{~d})$ ) produced a larger latent heat flux around the storm center that was helpful for storm development. As a result, the wind field was strengthened in the simulations with data assimilation.

4.3.4. Rainfall Simulation. Figure 10 compare the accumulated 3-hour precipitation around the storm center at 1800 UTC 02 October 2005. It shows that the precipitation near the region of $22 \mathrm{~N}$ and $43 \mathrm{~W}$ (northeast of the storm center) was well simulated in the experiments with data assimilation (DA Exp 1 and 2), compared to the control run results. Both the simulated quantity and location of the maximum rainfall are similar to the regional nature run. For the control run simulation, the simulated rainfall surrounding the storm center is relatively weak compared to the regional nature run.

To further examine the impact of the assimilation of DWL wind profiles on precipitation forecasts, the areaaveraged, storm-induced rainfall rates from different experiments were compared. Figure 11 illustrates the time series of the rainfall rate averaged in the region within a radius of $250 \mathrm{~km}$ from the storm center in different experiments compared with the results from the regional nature run between 1200 UTC 01 and 0600 UTC 03 October 2005. As shown in the figure, both the control run and the data assimilation experiments underestimated the rainfall rate as produced in the regional nature run. However, the data assimilation experiments (DA Exp1 and DA Exp2) improved the rainfall forecasts in the first 36 hours, although they did not perform well in the last 12 hours of the simulations.

\section{Summary and Discussions}

The potential impact of simulated Doppler Wind Lidar (DWL) wind profiles on the numerical simulation and prediction of tropical cyclones has been investigated using the WRF model and its 3DVAR data assimilation system by means of Observing System Simulation Experiments (OSSEs). Results indicated that, for this particular case, the assimilation of DWL wind profiles had the potential to improve both the horizontal and vertical wind structures and hence we could simulate stronger wind circulation. The simulated storm track and intensity were also improved after assimilation of DWL wind profiles during the 48hour simulation. Results from the two data assimilation experiments with different observation sampling strategies have shown that assimilating the wind observations around the storm center is useful for improving storm track and intensity simulations.

Future studies will be performed to evaluate the DWL wind observation impact with different sampling strategies, such as different horizontal and vertical resolutions of the measurements. A more comprehensive evaluation of the impacts of the DWL data on operational tropical cyclone forecasts will also be assessed using operational models and integrating the DWL data with all other conventional and satellite data available.

\section{Acknowledgments}

The computer time for this study was provided by NASA High-End Computing System and the Center for High Performance Computing (CHPC) at the University of Utah. Authors are grateful to Drs. Lars Peter Riishojggard and Michiko Masutani for providing ECMWF nature run data through a joint OSSE effort. The second author would like to thank Drs. G. David Emmitt, Bruce Gentry and Robert Atlas for useful discussion. This study is supported by NASA Grant no. NNX08AH88G.

\section{References}

[1] W. E. Baker, G. D. Emmitt, F. Robertson, et al., "Lidarmeasured winds from space: a key component for weather and climate prediction," Bulletin of the American Meteorological Society, vol. 76, no. 6, pp. 869-888, 1995.

[2] W. A. Lahoz, R. Brugge, D. R. Jackson, et al., "An observing system simulation experiment to evaluate the scientific merit of wind and ozone measurements from the future SWIFT 
instrument," Quarterly Journal of the Royal Meteorological Society, vol. 131, no. 606, pp. 503-523, 2005.

[3] A. Stoffelen, J. Pailleux, E. Källén, et al., "The atmospheric dynamics mission for global wind field measurement," Bulletin of the American Meteorological Society, vol. 86, no. 1, pp. 73-87, 2005.

[4] C. S. Velden, T. L. Olander, and S. Wanzong, "The impact of multispectral GOES-8 wind information on Atlantic tropical cyclone track forecasts in 1995. Part I: dataset methodology, description, and case analysis," Monthly Weather Review, vol. 126, no. 5, pp. 1202-1218, 1998.

[5] J. S. Goerss, C. S. Velden, and J. D. Hawkins, "The impact of multispectral GOES-8 wind information on Atlantic tropical cyclone track forecasts in 1995. Part II: NOGAPS forecasts," Monthly Weather Review, vol. 126, no. 5, pp. 1219-1227, 1998.

[6] I. Szunyogh, Z. Toth, R. E. Morss, S. J. Majumdar, B. J. Etherton, and C. H. Bishop, "The effect of targeted dropsonde observations during the 1999 Winter Storm Reconnaissance Program," Monthly Weather Review, vol. 128, no. 10, pp. 35203537, 2000.

[7] P. M. Boorman, R. Swinbank, and D. A. Ortland, "Assimilation of directly measured stratospheric winds into the Unified Model," Forecasting Research Technical Report 332, Met Office, 2000.

[8] L. Isaksen and A. Stoffelen, "ERS scatterometer wind data impact on ECMWF's tropical cyclone forecasts," IEEE Transactions on Geoscience and Remote Sensing, vol. 38, no. 4, pp. 1885-1892, 2000.

[9] L. Isaksen and P. A. E. M. Janssen, "Impact of ERS scatterometer winds in ECMWF's assimilation system," Quarterly Journal of the Royal Meteorological Society, vol. 130, no. 600, pp. 17931814, 2004.

[10] S. M. Leidner, L. Isaksen, and R. N. Hoffman, "Impact of NSCAT winds on tropical cyclones in the ECMWF 4DVAR assimilation system," Monthly Weather Review, vol. 131, no. 1, pp. 3-26, 2003.

[11] N. Žagar, "Assimilation of equatorial waves by line-of-sight wind observations," Journal of the Atmospheric Sciences, vol. 61, no. 15, pp. 1877-1893, 2004.

[12] G. J. Marseille and A. Stoffelen, "Simulation of wind profiles from a space-borne Doppler wind lidar," Quarterly Journal of the Royal Meteorological Society, vol. 129, no. 594, pp. 30793098, 2003.

[13] G.-J. Marseille, A. D. Stoffelen, and J. A. N. Barkmeijer, "Impact assessment of prospective spaceborne Doppler wind lidar observation scenarios," Tellus A, vol. 60, no. 2, pp. 234248, 2008.

[14] G.-J. Marseille, A. D. Stoffelen, and J. Barkmeijer, "A cycled sensitivity observing system experiment on simulated Doppler wind lidar data during the 1999 Christmas storm "Martin"," Tellus A, vol. 60, no. 2, pp. 249-260, 2008.

[15] S.-H. Chen, "The impact of assimilating SSM/I and QuikSCAT satellite winds on Hurricane Isidore simulations," Monthly Weather Review, vol. 135, no. 2, pp. 549-566, 2007.

[16] Z. Pu, X. Li, C. Velden, S. Aberson, and W. T. Liu, "Impact of aircraft dropsonde and usatellite wind data on the numerical simulation of two landfalling tropical storms during TCSP," Weather and Forecasting, vol. 23, pp. 62-79, 2008.

[17] D. G. H. Tan and E. Andersson, "Simulation of the yield and accuracy of wind profile measurements from the Atmospheric Dynamics Mission (ADM-Aeolus)," Quarterly Journal of the Royal Meteorological Society, vol. 131, no. 608, pp. 1737-1757, 2005.
[18] M. Weissmann and C. Cardinali, "Impact of airborne Doppler lidar observations on ECMWF forecasts," Quarterly Journal of the Royal Meteorological Society, vol. 133, no. 622, pp. 107-116, 2007.

[19] C. J. Grund, R. M. Banta, J. L. George, et al., "High-resolution doppler lidar for boundary layer and cloud research," Journal of Atmospheric and Oceanic Technology, vol. 18, no. 3, pp. 376393, 2001.

[20] C. P. Arnold Jr. and C. H. Dey, "Observing-systems simulation experiments: past, present and future," Bulletin of the American Meteorological Society, vol. 67, no. 6, pp. 687-695, 1986.

[21] R. M. Atlas, "Observing system simulation experiments: methodology, examples and limitations," in CGC/WMO Workshop, Geneva, Switzerland, April 1997, WMO TD No. 868.

[22] S. J. Lord, E. Kalnay, R. Daley, G. D. Emmitt, and R. Atlas, "Using OSSEs in the design of future generation integrated observing systems," in Proceedings of the 1st Symposium on Integrated Observing Systems, pp. 45-47, AMS, Long Beach, Calif, USA, 1997, preprints.

[23] D. F. Parrish and J. C. Derber, "The National Meteorological Center's spectral statistical-interpolation analysis system," Monthly Weather Review, vol. 120, no. 8, pp. 1747-1763, 1992.

[24] D. M. Barker, W. Huang, Y.-R. Guo, A. J. Bourgeois, and Q. N. Xiao, "A three-dimensional variational data assimilation system for MM5: implementation and initial results," Monthly Weather Review, vol. 132, no. 4, pp. 897-914, 2004.

[25] D. M. Barker, M. S. Lee, Y.-R. Guo, W. Huang, Q.-N. Xiao, and R. Rizvi, "WRF variational data assimilation development at NCAR," in Proceedings of the 5th WRF/14th MM5 Users' Workshop, p. 5, NCAR, Boulder, Colo, USA, 2004.

[26] M. Masutani, J. S. Woollen, S. J. Lord, et al., "Observing system simulation experiments at the National Centers for Environmental Prediction," Journal of Geophysical Research D, vol. 115, no. 7, Article ID D07101, 2010.

[27] O. Reale, J. Terry, M. Masutani, E. Andersson, L. P. Riishojgaard, and J. C. Jusem, "Preliminary evaluation of the European Centre for Medium-Range Weather Forecasts' (ECMWF) Nature Run over the tropical Atlantic and African monsoon region," Geophysical Research Letters, vol. 34, no. 22, Article ID L22810, 6 pages, 2007.

[28] Z. Pu, L. Zhang, B. Gentry, and B. Demoz, "Potential impact of lidar wind measurements on high-impact weather forecasting: a regional OSSEs study," in Proceedings of the 13th AMS Conference on Integrated Observing Systems for Atmosphere, Ocean, and Land Surface (IOAS-AOLS '09), Phoenix, Ariz, USA, January 2009.

[29] W. C. Skamarock, J. B. Klemp, J. Dudhia, et al., "A description of the advanced research WRF version 2," NCAR Technical Note NCAR/TN-468+STR, NCAR, Boulder, Colo, USA, 2005.

[30] W. Baker, "Concept for a US space-based wind lidar: status and current activities," in Joint Center for Satellite Data Assimilation (JCSDA) Seminar, July 2009.

[31] W. M. Frank and E. A. Ritchie, "Effects of vertical wind shear on the intensity and structure of numerically simulated hurricanes," Monthly Weather Review, vol. 129, no. 9, pp. 2249-2269, 2001.

[32] W. A. Nuss and R. A. Anthes, "A numerical investigation of low-level processes in rapid cyclogenesis," Monthly Weather Review, vol. 115, pp. 2728-2743, 1987.

[33] E. Rogers and L. F. Bosart, "A diagnostic study of two intense oceanic cyclones," Monthly Weather Review, vol. 119, no. 4, pp. 965-996, 1991. 
[34] G. H. Crescenti and R. A. Weller, "Analysis of surface fluxes in the marine atmospheric boundary layer in the vicinity of rapidly intensifying cyclones," Journal of Applied Meteorology, vol. 31, no. 8, pp. 831-848, 1992.

[35] P. J. Neiman and M. A. Shapiro, "The life cycle of an extratropical marine cyclone. Part I: frontal-cyclone evolution and thermodynamic air-sea interaction," Monthly Weather Review, vol. 121, no. 8, pp. 2153-2176, 1993.

[36] D.-L. Zhang, E. Radeva, and J. Gyakum, "A family of frontal cyclones over the western Atlantic Ocean. Part II: parameter studies," Monthly Weather Review, vol. 127, no. 8, pp. 1745$1760,1999$.

[37] N. Papasimakis, G. Cervone, F. Pallikari, and M. Kafatos, "Multifractal character of surface latent heat flux," Physics A, vol. 372, no. 2, pp. 703-718, 2006. 

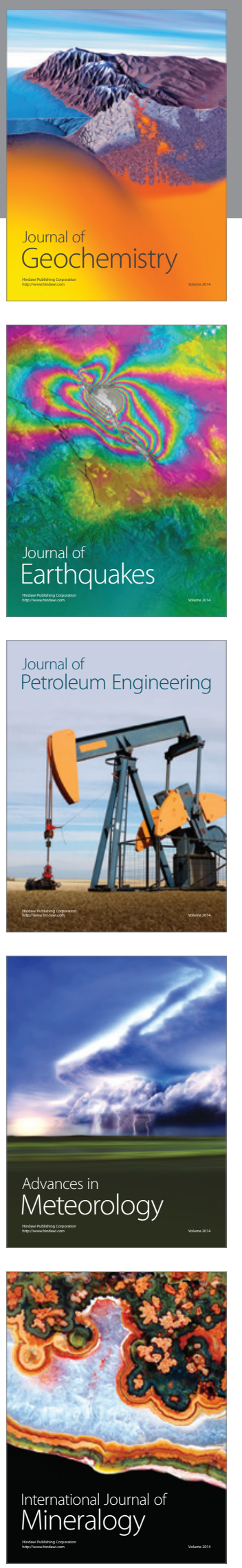
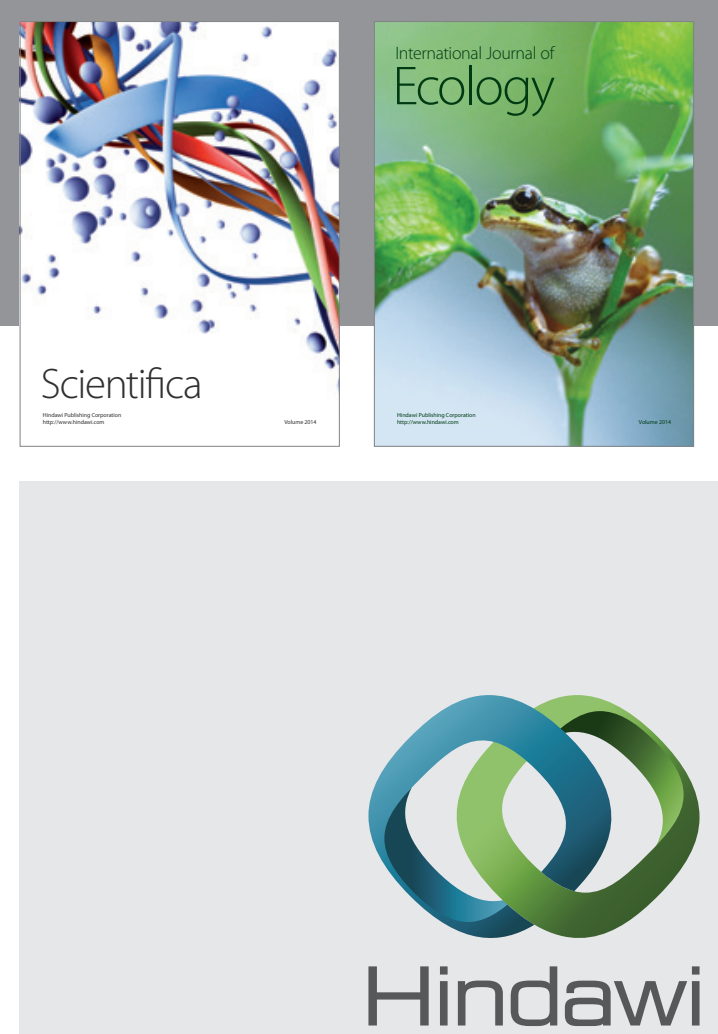

Submit your manuscripts at http://www.hindawi.com
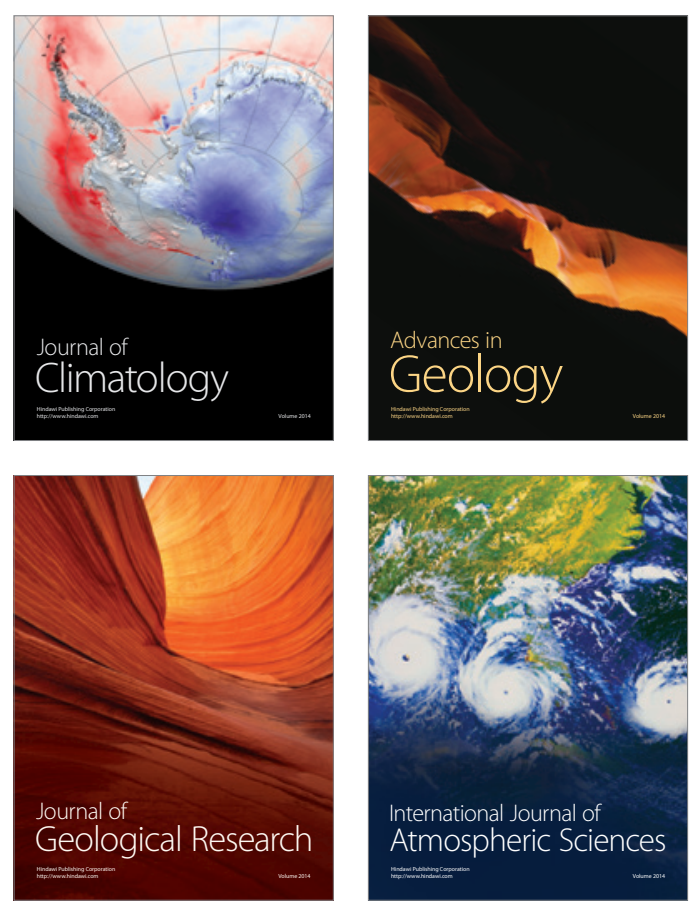
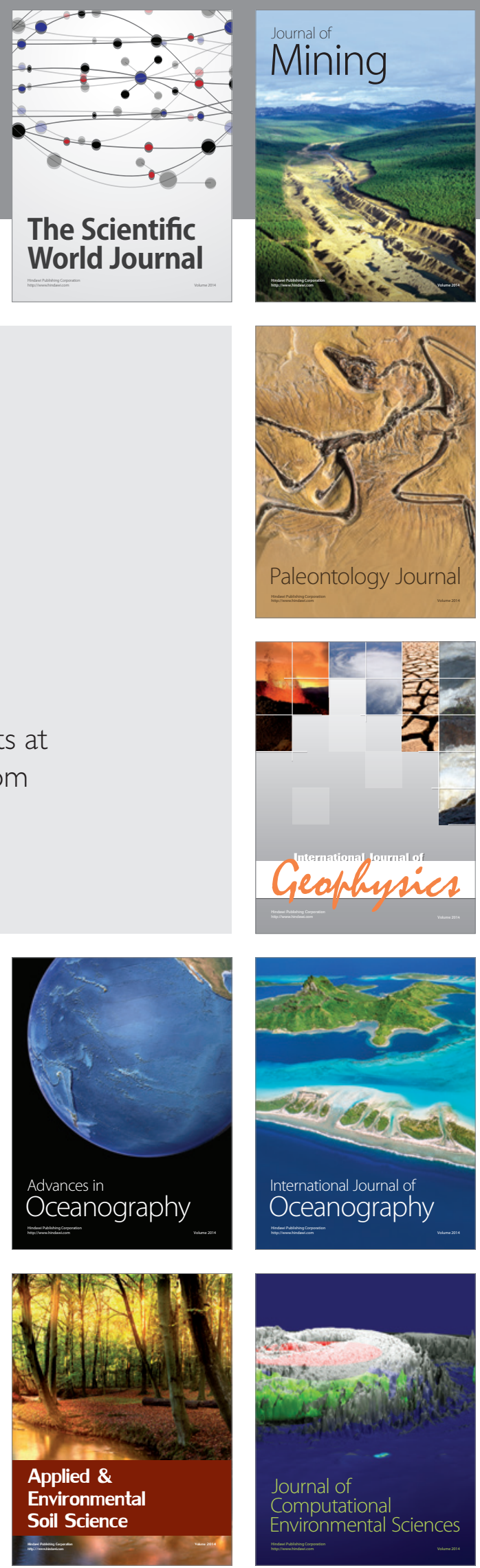